(c) American Dairy Science Association, 2006.

\title{
Comparison of Descriptive Sensory Analysis and Chemical Analysis for Oxidative Changes in Milk
}

\author{
R. V. Hedegaard, ${ }^{\star}$ D. Kristensen, ${ }^{\star}$ J. H. Nielsen,‡ M. B. Frøst,† H. Østdal,† \\ J. E. Hermansen,§ M. Kröger-Ohlsen, ${ }^{\star}$ and L. H. Skibsted ${ }^{\star 1}$ \\ ${ }^{*}$ Food Chemistry, and \\ †Sensory Science, Department of Food Science, The Royal Veterinary and Agricultural University, \\ Rolighedsvej 30, DK-1958 Frederiksberg C, Denmark \\ ‡Department of Animal Product Quality, and \\ $\S D e p a r t m e n t$ of Agroecology, Danish Institute of Agricultural Sciences, Research Centre Foulum, \\ DK-8830 Tjele, Denmark
}

\section{ABSTRACT}

Oxidation in 3 types of bovine milk with different fatty acid profiles obtained through manipulation of feed was evaluated by analytical methods quantifying the content of potential antioxidants, the tendency of formation of free radicals, and the accumulation of primary and secondary oxidation products. The milk samples were evaluated in parallel by descriptive sensory analysis by a trained panel, and the correlation between the chemical analysis and the descriptive sensory analysis was evaluated. The fatty acid composition of the 3 types of milk was found to influence the oxidative and lipolytic changes occurring in the milk during chill storage for $4 \mathrm{~d}$. Sensory analysis and chemical analysis showed high correlation between the typical descriptors for oxidation such as cardboard, metallic taste, and boiled milk and specific chemical markers for oxidation such as hexanal. Notably, primary oxidation products (i.e., lipid hydroperoxides) and even the tendency of formation of radicals as measured by electron spin resonance spectroscopy were also highly correlated to the sensory descriptors for oxidation. Electron spin resonance spectroscopy should accordingly be further explored as a routine method for detection of early events in lipid oxidation in milk to predict shelf-life.

Key words: bovine milk, manipulation through feed, fatty acid profile, oxidation

\section{INTRODUCTION}

Dairy products are known to oxidize during processing and storage, resulting in deterioration of flavor and nutritional value. It is well established that oxidation in processed dairy products is due to acceleration

Received July 13, 2005.

Accepted September 29, 2005.

${ }^{1}$ Corresponding author: LS@kvl.dk of oxidation processes already initiated in the raw milk. Several factors have been found to influence the extent of oxidation in the raw milk including the presence of different prooxidants such as transition metals $\left(\mathrm{Cu}^{2+}\right.$ and $\mathrm{Fe}^{3+}$ ) and the level of natural antioxidants such as the tocopherols, uric acid, and ascorbic acid. The degree of unsaturation in milk fat has a significant influence on oxidative stability of milk, as a higher proportion of unsaturated fatty acid results in inferior oxidative stability of raw milk (Sidhu et al., 1975; Barrefors et al., 1995; Havemose et al., 2004; Kristensen et al., 2004). Several studies show that sensory attributes of milk are affected by oxidation (Hermansen, 1995; Granelli et al., 1998); other studies have followed formation of primary and secondary oxidation products in milk in relation to feeding regimen, race, and stage in lactation (Palmquist et al., 1993; Fearon et al., 1996, 1998). However, studies of the correlation between oxidation described by analytical methods, including the tendency of formation of free radicals in the milk and descriptive sensory analysis, have not surfaced, despite the fact that establishment of such correlation would be most valuable for quality monitoring of raw milk and shelflife prediction.

Electron spin resonance (ESR) spectroscopy is a new and promising technique in dairy science. In addition to numerous specific applications, it may prove to be useful in predicting the oxidative stability of dairy products (Andersen et al., 2005). Electron spin resonance spectroscopy permits the direct detection of free radicals known as reaction intermediates in lipid oxidation and should be explored as a routine method for detection of early events in lipid oxidation in milk and for shelf-life prediction of dairy products. The aim of the present investigation was, accordingly, to establish any correlation between various chemical methods, both those more traditional and a method based on ESR spectroscopy, for detection of the different stages of oxidation and descriptive sensory analysis to produce rec- 
ommendations for chemical methods to monitor the development of off-flavor in milk and shelf-life prediction.

\section{MATERIALS AND METHODS}

\section{Experimental Design}

To produce milk types with different shelf-life, 6 cows were fed 3 different energy-balanced diets in a $3 \times 3$ Latin square design with periods of $3 \mathrm{wk}$ and 2 cows per diet in each period. The cows were all in midlactation and produced $>22 \mathrm{~kg}$ of milk/d with a cell count $<200,000$ SCC. The milk was routinely checked for its hygienic quality. At the end of each of the 3 -wk feeding periods, milk from 2 cows given the same diet was pooled. The experiment was conducted from October to January to produce milk in November, December, and January. The feed was produced at the feed plant at the Danish Institute of Agricultural Science. Milk samples were collected from the morning milking and were immediately cooled to $4^{\circ} \mathrm{C}$. The milk was not homogenized. The 3 types of feed selected were expected to result in different fatty acid profiles of the milk as follows.

Milk Type I. A low-fat diet was fed that was expected to offer a low content of citrate and high de novo lipid synthesis resulting in a high content of short-chain fatty acids in the milk fat. A roughage diet was supplemented with barley and crushed soybean meal and a mineral blend.

Milk Type II. A high-fat diet was fed that was expected to offer a high content of citrate and a relatively high content of unsaturated fatty acids. The diet included oatmeal and heat-treated full-fat soybeans and a mineral blend.

Milk Type III. A high-fat diet was fed that was expected to offer a high content of citrate and a high content of long-chain saturated fatty acids. The basal diet was supplemented with crushed soybean meal and a saturated fat with 50\% palmitic acid and 50\% stearic acid.

\section{Chemicals}

Water was purified through a Millipore Q-plus purification train from Millipore Corporation (Malshelm, France), $\beta$-carotene was obtained from Roche Ltd. (Hvidovre, Denmark), ethanol from De Danske Spritfabrikker (Aalborg, Denmark), 1,2,3-trihydroxybenzene (pyrogallol) from Aldrich (Steinheim, Germany), heptane HPLC grade and sodium chloride from Merck (Darmstadt, Germany), 2,6-di-t-butyl-p-cresol (butylated hydroxytoluene) from Sigma (St. Louis, MO), $\alpha$ tocopherol from Calbiochem (San Diego, CA), and Ntert-butyl- $\alpha$-phenylnitrone (PBN) from Aldrich. 2-Propanol, hexane, methanol HPLC grade, and trimethy- lamin synthetic grade were all from LAB-SCAN Co. (Dublin, Ireland), and nitrogen class 2 and helium were obtained from Hede Nielsen (Horsens, Denmark).

\section{Analysis of Fatty Acid Composition}

Prior to gas chromatography separation and quantification, the lipid was transesterified to methyl esters in a sodium methylate solution ( $2 \mathrm{~g}$ of methanol/L). Analysis of the fatty acid methyl esters was carried out with a gas chromatograph (Hewlett-Packard Co., Palo Alto, CA) using an FFAP-column (polyethylene glycol terephthalic acid $25 \mathrm{~m} \times 200 \mu \mathrm{m} \times 0.30 \mu \mathrm{m}$ ), helium as carrier gas, and a flame-ionization detector. Injection was splitless with an injector temperature of $250^{\circ} \mathrm{C}$. The detector temperature was $300^{\circ} \mathrm{C}$. The initial column temperature was $40^{\circ} \mathrm{C}$, which was held for $4 \mathrm{~min}$. The temperature was then raised at $10^{\circ} \mathrm{C} / \mathrm{min}$ to $240^{\circ} \mathrm{C}$, which was held for $1 \mathrm{~min}$. The fatty acid composition was identified and quantified via the use of external standards. The fatty acid compositions of each type of milk were measured at $\mathrm{d} 1$.

\section{Analysis of $\alpha$-Tocopherol}

The concentration of $\alpha$-tocopherol was determined by HPLC analysis after saponification and extraction with hexane. Samples $(800 \mathrm{mg})$ of milk were transferred to test tubes. Two milliliters of pyrogallol $(1 \mathrm{~g} / 100 \mathrm{~mL})$ was added to the samples, which then was saponified with $50 \%$ (wt/vol) $\mathrm{KOH}(0.3 \mathrm{~mL})$ at $70^{\circ} \mathrm{C}$ for $30 \mathrm{~min}$, followed by cooling on ice. Two milliliters of $\mathrm{H}_{2} \mathrm{O}$ and $4 \mathrm{~mL}$ of hexane containing butylated hydroxytoluene $(0.01 \mathrm{mg} / \mathrm{L})$ were added subsequently; the resulting suspension was centrifuged at $500 \times g$ for $10 \mathrm{~min}$. The upper phase was transferred to a test tube, and 3.0 $\mathrm{mL}$ of hexane was added followed by centrifugation. Finally, the solvent was removed from the pooled hexane extracts by evaporation under nitrogen. The residues were resuspended in $500 \mu \mathrm{L}$ of $96 \%$ ethanol. Quantification of tocopherol in the samples was performed with reverse-phase HPLC using $250 \mathrm{~mm} \times 4.6 \mathrm{~mm} \times 5$ $\mu \mathrm{m}, \mathrm{C} 18$ column (Chrompack, Melbur, The Netherlands) with methanol at a flow rate of $1.6 \mathrm{~mL} / \mathrm{min}$ as the mobile phase. Fluorescence detection $(292 / 330 \mathrm{~nm}$ excitation/emission) was used, using an external standard for identification and quantification. The content of $\alpha$-tocopherol in each type of milk was measured at d 1 and 4 after milking and with 3 replicates for each sample.

\section{Analysis of $\beta$-Carotene}

The concentration of $\beta$-carotene was determined by HPLC analysis after saponification and extraction with 
hexane. The saponification step for $\beta$-carotene determination was identical to the saponification step described previously for tocopherols, except that $500 \mathrm{mg}$ of milk instead of $800 \mathrm{mg}$ was used. The residues were resuspended in mobile phase consisting of heptane: isopronanol: trimethylamin (95:5:1, vol/vol). Quantification of $\beta$ carotene in the samples was performed with normal phase HPLC using a 250-mm $\times 4.6-\mathrm{mm}, 5-\mu \mathrm{m}$ C18 Supercosil $\mathrm{LC} \mathrm{NH}_{2}$ column. Detection was monitored at $450 \mathrm{~nm}$ using an external standard for identification and quantification. The content of $\beta$-carotene in each type of milk was measured at $\mathrm{d} 1$ and 4 after milking and with 3 replicates for each sample.

\section{Oxidative Stability Test Measured by ESR Spectroscopy}

Free radicals are paramagnetic and were detected by ESR spectroscopy, which is sensitive to paramagnetic compounds such as radicals (Andersen et al., 2005). To stabilize the very reactive free radicals prior to measurement, a spin-trapping technique was used. Using this technique, relative stable paramagnetic compounds, the spin adducts, are formed by reaction of radicals with ESR-silent compounds, the spin traps, added to the sample (Kristensen et al., 2002). The tendency of radical formation of the milk samples was measured by monitoring the growth of the spin adducts by ESR spectroscopy using the spin trap PBN as described by Kristensen et al. (2001). The relative signal height of the ESR spectra of milk incubated with 30 $\mathrm{mM}$ PBN at $55^{\circ} \mathrm{C}$ was measured after $200 \mathrm{~min}$, and the induction time for formation of radicals was determined. The ESR measurements for each type of milk were carried out at d 1 and after $4 \mathrm{~d}$ of storage.

\section{Lipid Hydroperoxides}

Primary oxidation products were analyzed as de-

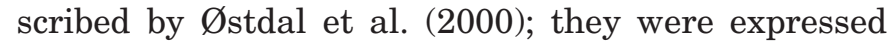
as relative content of lipid hydroperoxides and were measured at d 1, 2, 3, and 4 after milking with 3 replicates for each sample. Two-milliliter milk samples were mixed with $2 \mathrm{~mL}$ of $\mathrm{MeOH}$. Four milliliters of chloroform was added, and the samples were mixed for $30 \mathrm{~s}$ before centrifugation at $1,500 \times \mathrm{g}$ for $10 \mathrm{~min}$. To $1 \mathrm{~mL}$ of the lower phase was added $1 \mathrm{~mL}$ of iron-II/thiocyanate solution (solution I: $0.4 \mathrm{~g}$ of barium chloride dihydrate in $50 \mathrm{~mL}$ of $\mathrm{H}_{2} \mathrm{O}$ was mixed with $0.5 \mathrm{~g}$ of $\mathrm{FeSO}_{4}$ and 7 $\mathrm{H}_{2} \mathrm{O}$ in $50 \mathrm{~mL}$ of $\mathrm{H}_{2} \mathrm{O}$; the solution was filtered, and the filtrate was used. Solution II: $3 \mathrm{~g}$ of ammonium thiocyanate in $10 \mathrm{~mL}$ of $\mathrm{H}_{2} \mathrm{O}$. Solution III: $50 \mathrm{~mL}$ of chloroform mixed with $50 \mathrm{~mL}$ of $\mathrm{MeOH}$. The final ironII/thiocyanate solution was prepared by mixing $250 \mu \mathrm{L}$ of Solution I with $250 \mu \mathrm{L}$ of Solution II and adding 25 $\mathrm{mL}$ of Solution III to yield $25 \mathrm{~mL}$ ). The samples were left to react for $5 \mathrm{~min}$ at room temperature before the absorbance at $500 \mathrm{~nm}$ was measured on a HP-8453 diode array spectrophotometer (Agilent Technologies, Palo Alto, CA).

\section{2-Thiobarbituric Acid Reactive Substances}

The method for determination of 2-thiobarbituric acid reactive substances (TBARS) in milk according to King (1962) was used, and the result was expressed as the absorbance difference at $532 \mathrm{~nm}, 600 \mathrm{~nm}$, and absorbance at $450 \mathrm{~nm}$ as measured on a Cintra 40, UVVisable Spectrophotometer (Cintra, Victoria, Australia). The TBARS were measured at $\mathrm{d} 1$ and after $4 \mathrm{~d}$ of storage and with 2 replicates for each sample.

\section{Hexanal Content}

Hexanal accumulated in the stored milk was analyzed by solid-phase microextraction (SPME) in combination with gas chromatography flame ionization detection using an HP 6980 model from Hewlett-Packard Co. (Palo Alto, CA). Two milliliters of milk were filled in a 4-mL headspace vial cleaned by a gas flame with a glass-coated stirring bar; $0.25 \mathrm{~g}$ of $\mathrm{NaCl}$ was added to achieve a salting-out effect. An SPME fiber (CarboxenPDMS, $75 \mu \mathrm{m}$ ) from Supelco (Bellefonte, PA) was inserted in the headspace of the vial, which was equilibrated for 30 min while the temperature was held constant at $45^{\circ} \mathrm{C}$. Accelerated experiments were made by addition of $10 \mathrm{mM} \mathrm{Cu}$ (II) to the sample before analyzing. Analysis of the volatiles absorbed to the SPME fiber were carried out by gas chromatography using an HP-5 column (5\% phenyl methyl siloxane, $30 \mathrm{~m} \times 250$ $\mu \mathrm{m} \times 0.25 \mu \mathrm{m}$ ) from Hewlett-Packard Co.; helium was the carrier gas. Injection was performed in splitless mode with an injector temperature of $250^{\circ} \mathrm{C}$; the SPME fibers were desorbed for $5 \mathrm{~min}$. The initial column temperature was $40^{\circ} \mathrm{C}$, which was held for $4 \mathrm{~min}$, and the temperature was raised at $10^{\circ} \mathrm{C} / \mathrm{min}$ to $150^{\circ} \mathrm{C}$ and then to $250^{\circ} \mathrm{C}$ at $30^{\circ} \mathrm{C} / \mathrm{min}$. The content of hexanal was measured at d 1, 2, 3, and 4 after milking. Identification of hexanal was based on retention time, and verification was performed by gas chromatography-mass spectrometry for authentic hexanal.

\section{Acid Degree Value (Free Fatty Acids)}

The extent of lipolysis was estimated by the analysis of the acid degree value by the BDI-method (Singsaas and Hadland, 1972) and expressed as milliliters of $1 \mathrm{~N}$ $\mathrm{KOH} / 100 \mathrm{~g}$ of fat. The content of free fatty acids was 
Table 1. Sensory descriptors, their definitions, and reference materials

\begin{tabular}{lll}
\hline Descriptor & Definition (reference material) & Original Danish words \\
\hline Aroma & & Flødelugt \\
Cream aroma & Intensity of aroma of cream (13\% fat cream) & Kogt mælk lugt \\
Boiled milk aroma & Intensity of aroma of boiled milk (boiled, full-fat milk) & Gammelt smør lugt \\
Old butter aroma & Intensity of aroma of old butter (one small cube of old butter) & Pap lugt \\
Cardboard aroma & Intensity of aroma of cardboard (pieces of wet cardboard) & Harsk olie lugt \\
Rancid oil aroma & Intensity of aroma of rancid oil (rancid maize oil) & Plastik lugt \\
Plastic aroma & Intensity of aroma of plastic (inside of PET freeze bag) & Roquefort lugt \\
Roquefort aroma & Intensity of aroma of Roquefort (pieces of Roquefort cheese) & Hasselnød lugt \\
Hazel nut aroma & Intensity of aroma of hazelnuts (chopped hazelnuts) & Flødesmag \\
Flavor/taste & & Kogt mælk smag \\
Cream flavor & Intensity of cream flavor & Metallisk smag \\
Boiled milk flavor & Intensity of boiled milk flavor & Pap smag \\
Metallic taste & Intensity of metallic taste [0.6 g of Fe(II)sulfate/L of full-fat milk) & Roquefort smag \\
Cardboard flavor & Intensity of cardboard flavor & Hasselnød smag \\
Roquefort flavor & Intensity of Roquefort flavor & Sur smag \\
Hazelnut flavor & Intensity of hazelnut flavor & Sød smag \\
Sour taste & Intensity of sour taste & Eftermundfylde \\
Sweet taste & Intensity of sweet taste & \\
Mouth feel & & Degree of product left in the mouth after expectoration \\
Residual mouth fill & &
\end{tabular}

${ }^{1} \mathrm{PET}=$ Poly (ethyleneterephthalate)

measured at d 1 and 4 after milking with 2 replicates for each sample.

\section{Sensory Descriptive Analysis}

The milk samples were pasteurized $\left(63^{\circ} \mathrm{C}\right.$ for $\left.30 \mathrm{~min}\right)$ upon arrival at the Royal Veterinary and Agricultural University according to health regulations prior to descriptive sensory analysis performed in a sensory laboratory conforming to international standards for sensory analysis (ISO Standard 8589, 1988). Descriptive analysis was performed under normal light; the samples (approximately $35 \mathrm{~mL}$ ) were served in clear plastic containers with tight-fitting lids. The 3 types of milk were evaluated on $\mathrm{d} 1$ and 4 after milking. In each sensory session, 3 replicates were performed. Samples were served in randomized order over panelists within each replicate. Samples were kept at $16^{\circ} \mathrm{C}$ for $1 \mathrm{~h}$ prior to serving and taken out 1 to 2 min before serving. A panel consisting of 10 external, paid panelists was used for the evaluation. In trials 2 and 3, fewer panelists were available (9 in trial 2; 9 in trial 3 on d 1 and 8 on d 4). In 4 training sessions, panelists were trained on the products, and descriptors were chosen after suggestions from the panel leaders on the basis of consensus among the panelists. Each training session lasted approximately $1.5 \mathrm{~h}$. During training, panelists were presented with references for some of the descriptors. A total of 17 descriptors were selected for the descriptive analysis as listed in Table 1 together with their definitions, reference material, and original Danish words. Samples were scored on a computer screen using a 15$\mathrm{cm}$ unstructured scale; computerized score collection software (FIZZ, Biosystemes, Couternon, France) was used. The scales were anchored with "a little" and "a lot" ("lidt" and "meget," in Danish). For trials 1 and 3, panelists had a training session $4 \mathrm{~d}$ prior to evaluations to refresh their memory regarding the descriptors and the products. In these training sessions, examples of all samples that later would be evaluated were presented to the panelists.

\section{Statistical Analysis and Data Processing}

The results of the chemical analyses were subjected to ANOVA including the main effects and interaction of experiment number, feeding, and storage time using SAS version 6.12 software (SAS Inst., Inc., Cary, NC).

The results from the sensory evaluation were analyzed using descriptive univariate analyses (mean and ANOVA for each descriptor). Analyses of variance for the individual descriptors were performed considering the design as 6 individual products, not as 2 factors. This was done in order to closer examine the difference between storage effects in the 3 different milk types. Products were used as fixed factor, whereas cow pairs and panelists were used as random factors. Least significant differences were estimated based on mean square error.

Multivariate data analysis (partial least squares regression; PLSR) was applied to investigate relationships between sensory data and the experimental design (storage duration and milk type). The 3 cow pairs and 3 trials (November, December, and January) were also included to investigate differences between cows and season. Initially, data were analyzed to correct for 
Table 2. Fatty acid composition (mean percentages) of the Milk Type I, Milk Type II, and Milk Type III

\begin{tabular}{|c|c|c|c|}
\hline Fatty acid & $\begin{array}{l}\text { Milk } \\
\text { Type I }\end{array}$ & $\begin{array}{l}\text { Milk } \\
\text { Type II }\end{array}$ & $\begin{array}{l}\text { Milk } \\
\text { Type III }\end{array}$ \\
\hline Butyric acid (C4) & $4.70^{\mathrm{a}}$ & $4.88^{\mathrm{a}}$ & $4.13^{\mathrm{b}}$ \\
\hline Caproic acid (C6) & $3.06^{\mathrm{a}}$ & $2.91^{\mathrm{a}}$ & $2.18^{\mathrm{b}}$ \\
\hline Caprylic acid (C8) & $1.63^{\mathrm{a}}$ & $1.50^{\mathrm{a}}$ & $0.88^{\mathrm{b}}$ \\
\hline Capric acid (C10) & $3.78^{\mathrm{a}}$ & $3.02^{\mathrm{b}}$ & $1.76^{\mathrm{c}}$ \\
\hline Lauric acid (C12) & $4.57^{\mathrm{a}}$ & $3.22^{\mathrm{b}}$ & $2.09^{c}$ \\
\hline Myristic acid (C14) & $13.05^{\mathrm{a}}$ & $11.09^{b}$ & $8.21^{\mathrm{c}}$ \\
\hline Palmitic acid (C16) & $43.58^{\mathrm{b}}$ & $27.32^{\mathrm{c}}$ & $61.78^{\mathrm{a}}$ \\
\hline Palmitoleic acid (C16:1) & $1.73^{\mathrm{b}}$ & $1.04^{\mathrm{b}}$ & $3.06^{\mathrm{a}}$ \\
\hline Margaric acid (C17) & $0.69^{\mathrm{a}}$ & $0.51^{\mathrm{b}}$ & $0.33^{\mathrm{c}}$ \\
\hline Stearic acid (C18:0) & $7.68^{b}$ & $14.80^{\mathrm{a}}$ & $3.86^{\mathrm{c}}$ \\
\hline Oleic acid (C18:1) & $13.24^{\mathrm{b}}$ & $24.98^{\mathrm{a}}$ & $10.47^{\mathrm{c}}$ \\
\hline Linoleic acid (C18:2) & $1.67^{\mathrm{b}}$ & $3.90^{\mathrm{a}}$ & $0.95^{\mathrm{c}}$ \\
\hline$\gamma$-Linolenic acid (C18:3) & $0.62^{b}$ & $0.81^{\mathrm{a}}$ & $0.29^{c}$ \\
\hline
\end{tabular}

${ }^{\mathrm{a}-\mathrm{c}}$ Samples with different characters in the same row are significantly different from each other at the 0.05 level.

differences between panelists by PLSR (level correction), and level-corrected data were used for analysis of effects of different treatments. After level correction, data were averaged over panelists, and those data were used for further analysis of relationships with chemical data. For all of the multivariate analyses, cross validation was performed, leaving each trial out at a time (Martens and Næs, 1989). The analyses were performed in standard statistical software packages (SPSS 9.0.0, SPSS Inc., Chicago, IL, for the univariate statistics and Unscrambler 7.51a, Camo A/S, Trondheim, Norway, for the multivariate data analysis).

\section{RESULTS}

The relative fatty acid composition of the 3 milk types including all 3 trials (November, December, and January) showed a different fatty acid profile for the 3 types of milk (Table 2). Milk Type I contained a significantly higher amount of de novo synthesized fatty acids such as $\mathrm{C} 10, \mathrm{C} 12$, C14, and C16, whereas Milk Type II contained a considerable higher quantity of unsaturated fatty acids, and Milk Type III contained significantly

Table 3. The content of tocopherols and $\beta$-carotene in the 3 milk types during a storage period of $4 \mathrm{~d}$

\begin{tabular}{lllc}
\hline & $\begin{array}{l}\text { Storage } \\
\text { days }\end{array}$ & $\begin{array}{l}\alpha \text {-tocopherol } \\
(\mu \mathrm{g} / \mathrm{g} \text { of milk })\end{array}$ & $\begin{array}{l}\beta \text {-carotene } \\
(\mu \mathrm{g} / \mathrm{g} \text { of milk })\end{array}$ \\
\cline { 3 - 4 } & & $1.63 \pm 0.4$ & $0.25 \pm 0.08$ \\
Milk Type I & 1 & $1.65 \pm 0.54$ & $0.19 \pm 0.04$ \\
Milk Type II & 1 & $1.13 \pm 0.16$ & $0.13 \pm 0.06$ \\
Milk Type III & 1 & $1.58 \pm 0.31$ & $0.25 \pm 0.07$ \\
Milk Type I & 4 & $1.73 \pm 0.53$ & $0.18 \pm 0.05$ \\
Milk Type II & 4 & $1.17 \pm 0.21$ & $0.10 \pm 0.03$ \\
Milk Type III & 4 & &
\end{tabular}

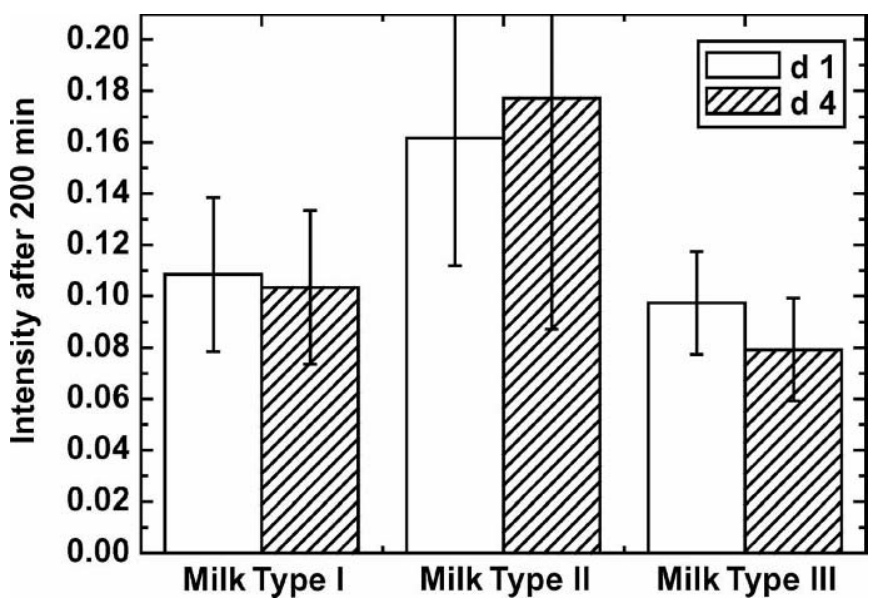

Figure 1. Relative signal height of electron spin resonance spectra for milk incubated with $30 \mathrm{~m} M$ of the spin trap N-tert-butyl- $\alpha$-phenylnitrone at $55^{\circ} \mathrm{C}$ for Milk Type I, Milk Type II, and Milk Type III at d 1 with standard deviations as marked.

higher amounts of saturated fatty acids dominated by palmitic acid. There were no significant differences between the content of the fat-soluble antioxidants in the 3 types of milk, and the concentration of $\alpha$-tocopherol and $\beta$-carotene did not change significantly during storage in any of the 3 types of milk (Table 3 ).

The tendency to form radicals in the 3 types of milk was analyzed by ESR spectroscopy by transforming short-lived radicals into longer-lived spin adducts by using the spin trap PBN. The intensity of the signal from the spin adducts is proportional to radicals formed in the milk and can accordingly be use as a relative measure of the concentration of radicals accumulating over a certain period of time. The formation of radicals was found to be higher in Milk Type II (Figure 1), which contained more unsaturated fatty acids compared with the other 2 types of milk. The lowest formation of radicals was found in Milk Type III, which had the lowest concentration of unsaturated fatty acids (Figure 1). There were no significant differences in the formation of radicals as a consequence of storage for the 3 milk types.

In the ESR spectra, a well-defined induction time prior to a linear increase in the signals caused by the formation of spin adducts was noted. The length of the induction time is a measure of the balance between pro- and antioxidants. Milk Type III had the longest induction time (Table 4), suggesting a slower depletion of antioxidants in this type of milk compared with the other 2 types of milk. Milk Type II had a long induction time at d 1 (Table 4), which, however, decreased during storage to a shorter induction time, indicating a change in the balance between pro- and antioxidants. 
Table 4. Tendency of formation of radicals in milk measured as induction time and with relative intensity of spin adducts after 200 min in electron spin resonance spin-trapping assay

\begin{tabular}{llcc}
\hline & Day & $\begin{array}{l}\text { Induction } \\
\text { time }(\mathrm{min})\end{array}$ & $\begin{array}{l}\text { Intensity } \\
\text { at 200 min }\end{array}$ \\
\cline { 3 - 4 } & & $120 \pm 34.6$ & $0.11 \pm 0.03$ \\
Milk Type I & 1 & $67 \pm 20.8$ & $0.16 \pm 0.05$ \\
Milk Type II & 1 & $125 \pm 44.4$ & $0.10 \pm 0.02$ \\
Milk Type III & 1 & $77 \pm 25.2$ & $0.10 \pm 0.03$ \\
Milk Type I & 4 & $70 \pm 30$ & $0.18 \pm 0.009$ \\
Milk Type II & 4 & $140 \pm 52$ & $0.080 \pm 0.02$ \\
Milk Type III & 4 & &
\end{tabular}

The relative content of lipid hydroperoxides in the 3 types of milk is shown in Table 5 as the absorbance at $500 \mathrm{~nm}$. The initial concentration of lipid hydroperoxides was identical in the 3 types of milk. There was a clear effect of storage as the content of lipid hydroperoxides increased during storage in all 3 types of milk (Table 4), but without a significant difference between the 3 types of milk.

The accumulation of secondary oxidation products was followed using the accumulation of hexanal together with TBARS as markers of secondary oxidation. The content of hexanal increased during storage in each of the 3 types of milk (Table 5), and Milk Type II was found to have the highest content of hexanal after $4 \mathrm{~d}$ of storage. To accelerate lipid oxidation, $\mathrm{CuSO}_{4}$ was added to each of the 3 types of milk to yield a final concentration of $10 \mu M$, and the accumulation of hexanal was followed in the 3 milk types. The results clearly show that addition of $\mathrm{Cu}$ (II) accelerates lipid oxidation and that the most unsaturated milk (Milk Type II) oxidizes more rapidly than the other 2 milk types. The TBARS of the milk was used as another marker for accumulation of secondary lipid oxidation products; however, development in TBARS was insignificant (Table 5) in each of the 3 milk types. Storage did not affect TBARS for any of the milk types, although a tendency for an increasing TBARS value during storage for Milk
Type II was observed. However, the differences between the 3 milk types were not found to be significant.

In addition to oxidative changes, the degree of lipolysis was followed for the 3 milk types. Milk Type III was found to have significantly higher acid degree values in all replicates $(P<0.0001)$ compared with Milk Type I and Milk Type II (Table 5). No significant influence of storage time was found, however, in any of the milk types.

\section{Sensory Descriptive Analysis}

The ANOVA for the individual descriptors indicated that 14 of the 17 descriptors showed significant differences over the products. Table 6 provides an overview of all products for those 14 descriptors, also listing least significant differences at the $5 \%$ level. The remaining 3 descriptors were excluded from further analysis of the data, as they did not contribute to discrimination among the 6 products ( 3 types of milk prior to and following storage).

After preprocessing of the data (level correction to account for different use of scale by panelist and exclusion of nonsignificant sensory descriptors), ANOVAPLSR was performed (design as X-variables and sensory data as Y-variable). The PLSR model needs 4 dimensions to account for all systematic variation in the sensory data (validated by cross-validation). Dimensions 1 to 4 explain $50,8.4,2.6$, and $1.7 \%$ of the variation in the sensory data, respectively. Figure 2 shows correlation-loading plots from the first 2 significant dimensions, explaining the differences between milk types and duration of storage. Dimensions 3 and 4 account for only a small fraction of the total variance. The systematic variance in the 2 dimensions mainly explains the subtle difference among the 3 different pairs of cows used in the experiment. Jack-knife estimation (Martens and Martens, 2000) of the design variables (feed type, storage, cow pairs, and trials) shows that neither cow pairs nor trials are influencing the model significantly,

Table 5. Relative oxidative and lipolytic changes of 3 types of milk with different fatty acid compositions. A = Absorbance; TBARS $=2$ thiobarbituric acid reactive substance.

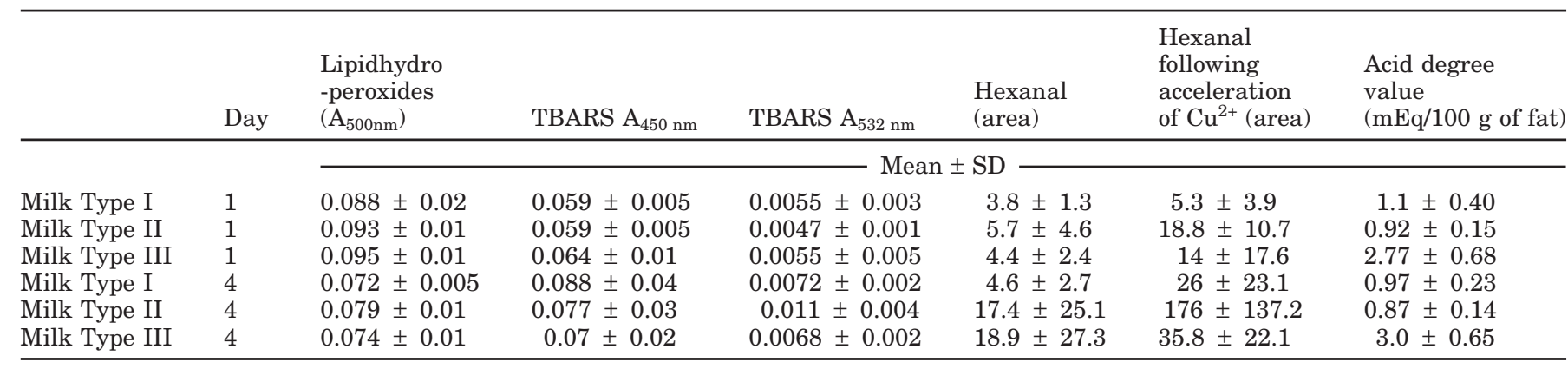


Table 6. Means for all samples and significant descriptors as calculated over replicates and panelists (81 or 84 observations for each value $\left.{ }^{1}\right)$ and LSD values $(P<0.05)$. Scale $=15$-cm unstructured scale anchored with "a little" and "a lot" ("lidt" and "meget", in Danish). Abbreviations in plots refer to milk type [Milk Type I-Milk Type III (M1-M3) and storage in days (d 1-4)]

\begin{tabular}{|c|c|c|c|c|c|c|c|c|c|}
\hline \multirow[b]{2}{*}{$\begin{array}{l}\text { Abbreviation } \\
\text { in plots }\end{array}$} & \multirow[b]{2}{*}{$\begin{array}{l}\text { Milk } \\
\text { Type }\end{array}$} & \multirow[b]{2}{*}{$\begin{array}{l}\text { Storage } \\
\text { (d) }\end{array}$} & \multicolumn{7}{|c|}{ Aroma } \\
\hline & & & Cream & $\begin{array}{l}\text { Boiled } \\
\text { milk }\end{array}$ & $\begin{array}{l}\text { Old } \\
\text { butter }\end{array}$ & $\begin{array}{l}\text { Card- } \\
\text { board }\end{array}$ & $\begin{array}{l}\text { Rancid } \\
\text { oil }\end{array}$ & $\begin{array}{l}\text { Roque- } \\
\text { fort }\end{array}$ & Hazelnut \\
\hline M1D1 & I & 1 & 5.77 & 5.67 & 3.73 & 4.49 & 2.86 & 2.30 & 3.35 \\
\hline M2D1 & II & & 5.95 & 5.76 & 3.33 & 4.33 & 2.87 & 2.38 & 3.48 \\
\hline M3D1 & III & & 6.51 & 5.88 & 6.00 & 3.90 & 3.76 & 4.53 & 2.92 \\
\hline M1D4 & I & 4 & 6.03 & 5.83 & 3.71 & 4.33 & 2.64 & 2.46 & 2.96 \\
\hline M2D4 & II & & 5.82 & 6.55 & 3.85 & 5.64 & 3.15 & 3.05 & 3.05 \\
\hline \multirow[t]{4}{*}{ M3D4 } & III & & 5.92 & 6.02 & 6.05 & 3.96 & 3.83 & 4.87 & 2.23 \\
\hline & LSD & & 0.73 & 0.76 & 0.74 & 0.77 & 0.61 & 0.73 & 0.64 \\
\hline & & & \multicolumn{5}{|c|}{ Flavor } & \multicolumn{2}{|c|}{ Taste } \\
\hline & & & $\begin{array}{l}\text { Boiled } \\
\text { milk }\end{array}$ & Metallic & $\begin{array}{l}\text { Card- } \\
\text { board }\end{array}$ & $\begin{array}{l}\text { Roque- } \\
\text { fort }\end{array}$ & Hazelnut & Sour & Sweet \\
\hline M1D1 & I & 1 & 5.22 & 4.04 & 3.76 & 2.00 & 4.01 & 4.43 & 5.98 \\
\hline M2D1 & II & & 5.44 & 3.97 & 3.95 & 1.93 & 4.12 & 4.57 & 5.90 \\
\hline M3D1 & III & & 5.81 & 4.73 & 4.27 & 4.51 & 2.79 & 6.41 & 4.66 \\
\hline M1D4 & I & 4 & 5.61 & 4.57 & 4.32 & 2.48 & 3.65 & 4.87 & 5.78 \\
\hline M2D4 & II & & 6.10 & 5.58 & 5.57 & 2.56 & 3.74 & 5.06 & 6.06 \\
\hline M3D4 & III & & 6.22 & 5.14 & 4.52 & 4.41 & 2.32 & 6.53 & 4.81 \\
\hline & LSD & & 0.73 & 0.81 & 0.80 & 0.70 & 0.65 & 0.95 & 0.81 \\
\hline
\end{tabular}

${ }^{1}$ Either 9 or 6 missing values because of sickness among panelists on various evaluation days.

i.e., the cows in each subgroup in the full cross-over design responded similarly to the feed with regard to effect on sensory properties of the milk.

In dimension 1, 2 clusters of descriptors are seen. One group, consisting of sweet taste and hazelnut aroma and flavor, which are normally associated with fresh milk, related to Milk Types I and II, as they have a relatively high intensity of these descriptors. At the opposite end is a group related to Milk Type III. Those scores were higher in others descriptors such as of rancid oil aroma, old butter aroma, sour taste, and Roquefort flavor and aroma. Thus, dimension 1 describes the differences between Milk Type I and II, which initially are very similar, vs. Milk Type III. These observations can be confirmed by close inspection of Table 6 . Dimension 2 describes the effect of increasing the storage duration. There is an increase in the intensity of the descriptors metallic flavor, cardboard flavor, and cardboard aroma and, to a lesser degree, increases in boiled milk flavor and boiled milk aroma. Increasing the storage duration from 1 to $4 \mathrm{~d}$ has varied effect on the 3 different milk types. Storage duration has larger influence on the sensory properties of Milk Type II, and there is a rather large increase in the intensity of especially metallic flavor and cardboard flavor and aroma (Table 6 ). The changes in the 2 other milk types are less dramatic. Close inspection of Table 6 shows that the changes in intensity of the descriptors affected by storage duration have the same pattern for the other 2 descriptors as well, but none of the differences within milk type are significant.

\section{DISCUSSION}

A good correlation was found between specific chemical analysis and the sensory data when looking at the first 2 dimensions of the ANOVA-PLSR score plot (Figure 2). The sensory properties were not the same for the 3 types of milk, corresponding to differences in the fatty acid profiles of milk and leading to dissimilar chemical reaction pathways taking place in the milk during storage. Milk Type I did not show large sensory differences during storage for $4 \mathrm{~d}$ and did not show considerable changes in the values of chemical analysis associated with either lipolysis or oxidation. Milk Type II contained more unsaturated fatty acids than the other 2 types of milk and was more sensitive to oxidation. It was initially similar to Milk Type I, but Milk Type II changed during storage (Figure 2). The oxidative changes in Milk Type II were attributed to the prooxidative effect of unsaturated fatty acids and could be observed as a higher intensity of spin adducts formed in Milk Type II and observed as higher intensity of the ESR signals following $200 \mathrm{~min}$ of incubation (Figure 1). The more unsaturated fatty acids present in Milk Type II than the other types of milk resulted in faster formation of radicals initiating oxidative damage to the milk. 


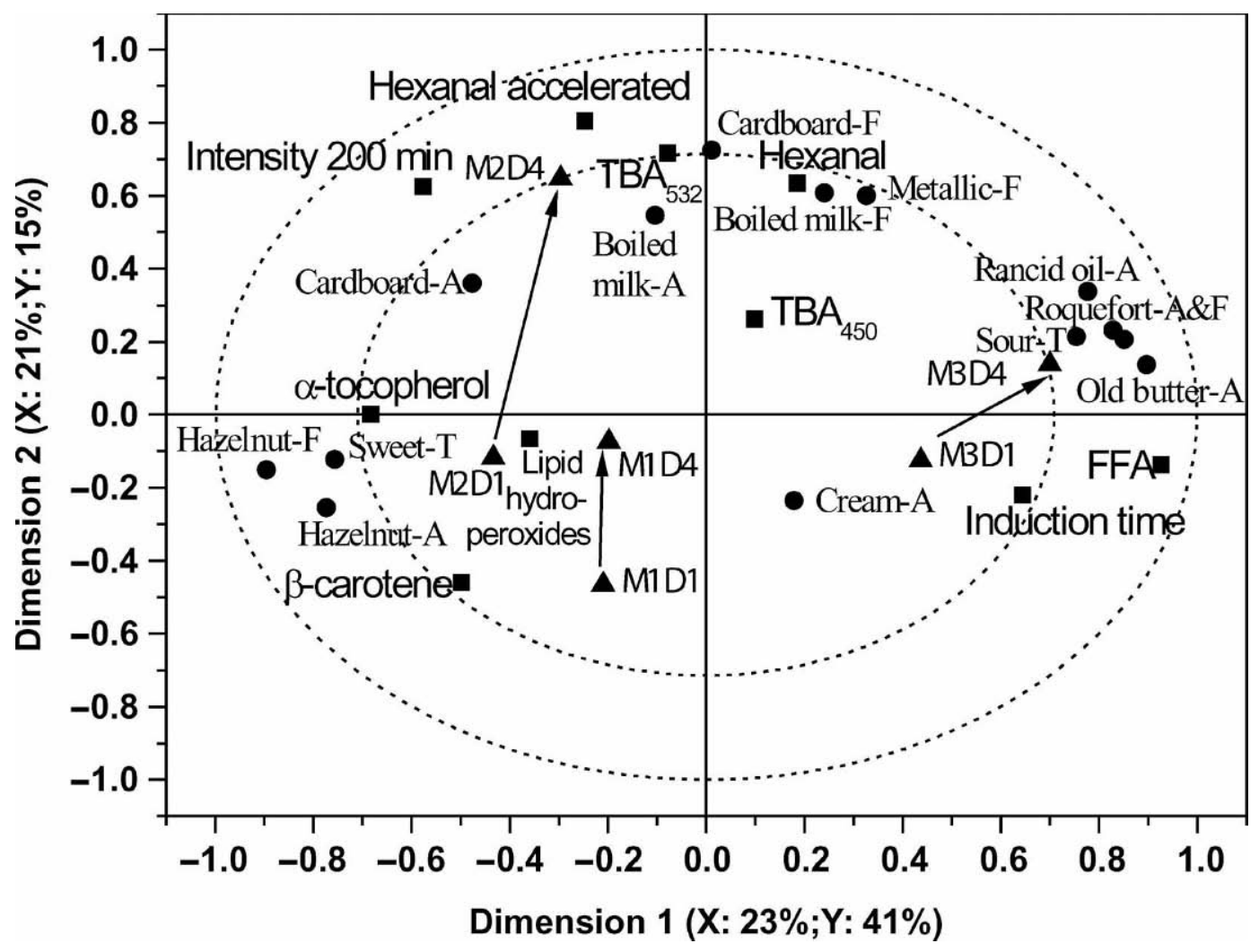

Figure 2. A partial least squares regression correlation loading plots for the first 2 dimensions, showing differences among the 6 products (M1D1, M1D4, M2D1, M2D4, M3D1, and M3D4) on d 1 and 4 after milking, their sensory descriptors, and chemical analyses. The inner and outer circles represent 50 and 100\% explained variance, respectively. Refer to Table 1 for sensory descriptors applied and to Tables 3 and 4 for chemical analysis. The arrows in the plots illustrate the changes during storage for the 3 types of milk. FFA = free fatty acid; $\mathrm{TBA}=$ thiobarbituric acid .

The sensory analysis of Milk Type II correlated with these findings and clearly showed an increase in the intensity of the descriptors metallic flavor, cardboard flavor, and cardboard aroma and to a lesser degree increases in boiled milk flavor and boiled milk aroma, descriptors normally related to the oxidation processes (Wiking et al., 2002; Frandsen et al., 2003). The concentration of hexanal and the values of TBARS measured at $532 \mathrm{~nm}$ correlated with the sensory descriptors normally associated with oxidation (Figure 2), although a difference among the 3 types of milk and effect of storage was not seen. Previous studies have shown a high correlation between oxidation of dairy products and the yellow color of TBARS (450 nm), which have been related to oxidation of monounsaturated fatty acids. In contrast, the pink pigment TBARS $(532 \mathrm{~nm})$ traditionally used in TBARS measurements has been assigned to oxidation reactions of polyunsaturated fatty acids (Stapelfeldt et al., 1997). However, these suggestions were not further supported by the results of the present study. It should, however, be noted that the value for TBARS (both 532 and $450 \mathrm{~nm}$ ) in milk often is close to the detection limit. In Type 2 milk, the relative amount of unsaturated acids is high compared with what is usually found in milk, and this was expected to make the correlation between off-flavors associated with oxidation and the TBARS even more pronounced, but this was not seen (Table 5).

Good correlations between the accelerated hexanal measurement, where $\mathrm{Cu}$ (II) had been added, and the sensory descriptor associated with oxidation (e.g., metallic flavor, cardboard flavor, and to some degree boiled milk flavor) were also found (Figure 2). Addition of $\mathrm{Cu}$ (II) in the experiment where oxidation in milk is measured, thus seems possible as an accelerated method to predict the oxidative stability prior to storage. Hexanal also is present in a higher concentration when oxidation is accelerated by $\mathrm{Cu}^{2+}$ as compared with the spontaneously formed hexanal, which is near to the detection limit of the gas chromatography method. In contrast, no correlation between the sensory descriptors for oxidation and the concentration of lipid hydroperoxides or TBARS measured at $450 \mathrm{~nm}$ was found. As for the peroxides, this confirms the generally accepted 
assumption that lipid hydroperoxides are neutral in oils and fats with respect to flavor (Frankel, 2005).

Milk Type 3 seems stable in relation to oxidation but is found to contain high levels of free fatty acids (Table 5 ) already from $d 1$, and the normal sensory descriptors for lipolysis, e.g., rancid and Roquefort, were highly correlated to the accumulation of free fatty acids. Lipolysis was very pronounced in Milk Type III, which contained larger amounts of free fatty acids already from d 1 (Table 5) in accordance with previous findings by Wiking et al. (2003) for milk containing high concentrations of palmitate.

The length of the lag phase of the ESR signals for radicals trapped by PBN correlates with the oxidation descriptors for Type III milk found to be oxidative stable (Figure 2). During storage of the 3 milk types, the amount of prooxidants seems to have increased relative to the amount of antioxidant becoming depleted by oxidation processes. This is most pronounced for Type II milk, because of a larger content of unsaturated fatty acids. The lag phase of Type III milk is longer because of the higher saturation; the consumption of antioxidant accordingly is smaller. The induction time of Type III milk was accordingly longer, and the milk was more resistant to formation of radicals compared with the 2 other milk types.

In conclusion, the fatty acid composition of 3 types of milk was found to influence initial oxidation and lipolysis and subsequent changes taking place during storage measured both by chemical analysis and sensory descriptive analysis. The sensory properties of Milk Type III were very different from the 2 other types of milk, as this milk was more exposed to lipolysis compared with the other 2 types of milk. Milk of Type I and II were similar when fresh, but behaved differently during storage, as Milk Type I was relatively unaffected by storage, whereas Type II milk oxidized significantly between $\mathrm{d} 1$ and 4 . Chemical measurement of the secondary oxidation product, such as hexanal, correlated well with sensory descriptors, and the 3 types of milk could be differentiated by fatty acid profile and by the effect of storage. The TBARS measured as absorbance at $532 \mathrm{~nm}$ was found to correlate with sensory descriptors and other oxidation parameters but showed no significant difference among the 3 types of milk or with storage time. The TBARS measured as absorbance at $450 \mathrm{~nm}$ showed no correlation with the sensory descriptors, and TBARS must, in general, be considered to be a less valuable method. Most interesting is the high correlation found between the radical intensity measured by the spin-trapping technique and of antioxidant capacity measured by lag face (ESR) and the sensory descriptors for oxidation, indicating that the early event of radical formation can be used to predict generation of off-flavors during storage as a consequence of oxidation. Low-cost ESR spectrometers are now becoming available and should be considered for use for prediction of shelf-life by the dairy industry.

\section{ACKNOWLEDGMENT}

Kirsten Metz and Pia Moesgaard Poulsen are thanked for excellent technical assistance. This research was performed as part of a collaboration project between LMC-Center for Advances Food Studies and the Danish Dairy Research Foundation as part of the FØTEK program.

\section{REFERENCES}

Andersen, M. L., J. Velasco, and L. H. Skibsted. 2005. Analysis of lipid oxidation by ESR spectroscopy. Pages 127-151 in Analysis of Lipid Oxidation. A. Kamal-Eldin and J. Pokorbý, ed. AOCS Press, Champaign, IL.

Barrefors, P., K. Granelli, L.-A. Appelqvist, and L. Bjoerck. 1995. Chemical characterization of raw milk samples with and without oxidative off-flavor. J. Dairy Sci. 78:2691-2699.

Fearon, A. M., C. S. Mayne, and C. T. Charlton. 1998. Effect of naked oats in the dairy cows diet on the oxidative stability of the milk fat. J. Sci. Food Agric. 76:546-552.

Fearon, A. M., C. S. Mayne, and S. Marsden. 1996. The effect of including naked oats in the concentrate offered to dairy cows on milk production, milk fat composition and properties. J. Sci. Food Agric. 72:273-282.

Frandsen, L. W., G. Dijksterhuis, P. Brockhoff, J. H. Nielsen, and M. Martens. 2003. Subtle differences in milk: Comparison of an analytical and an affective test. Food Qual. Pref. 14:515-526.

Frankel, E. N. 2005. Methods to determine extent of oxidation. Chapter 5 in Lipid Oxidation. 2nd ed. E. N. Frankel, ed. The Oily Press, Bridgwater, UK.

Granelli, K., P. Barrefors, L. Bjoerck, and L.-A. Appelqvist. 1998. Further studies on lipid composition of bovine milk in relation to spontaneous oxidised flavour. J. Sci. Food Agric. 77:161-171.

Havemose, M. S., M. R. Weisbjerg, W. L. P. Bredie, and J. H. Nielsen. 2004. Influence of feeding different types of roughage on the oxidative stability of milk. Int. Dairy J. 14:563-570.

Hermansen, J. E. 1995. Prediction of milk fatty acid profile in dairy cows fed dietary fat differing in fatty acid composition. J. Dairy Sci. 78:872-879.

ISO Standard 8589. 1988. Sensory Analysis-General Guidance for the Design of Test Rooms. ISO, Geneva, Switzerland.

King, R. L. 1962. Oxidation of milk fat globule membrane material. I. Thiobarbituric acid reaction as a measure of oxidized flavor in milk and models systems. J. Dairy Sci. 45:1165-1171.

Kristensen, D., M. L. Andersen, and L. H. Skibsted. 2001. Prediction of oxidative stability of raw milk using spin trapping electron spin resonance spectroscopy. Milchwissenschaft 57:255-258.

Kristensen, D., R. V. Hedegaard, J. H. Nielsen, and L. H. Skibsted. 2004. Oxidative stability of buttermilk as influenced by fatty acid composition of cows' milk manipulated by diet. J. Dairy Res. 71:46-50.

Kristensen, D., M. V. Kröger-Ohlsen, and L. H. Skibsted. 2002. Radical formation in dairy products: Prediction of oxidative stability based on electron spin resonance spectroscopy. Pages 114-125 in ACS Symp. Series 807. American Chemical Society, Washington, DC.

Martens, H., and M. Martens. 2000. Modified jack-knife estimation of parameter uncertainty in bilinear modelling by partial least squares regression (PLSR). Food Qual. Pref. 11:5-16.

Martens, H., and T. Næs. 1989. Multivariate Calibration. Chichester. J. Wiley \& Sons, Ltd., Chichester, UK. 
Østdal, H., H. J. Andersen, and J. H. Nielsen. 2000. Antioxidative activity of urate in bovine milk. J. Agric. Food Chem. 48:55885592.

Palmquist, D. L., A. D. Beaulieu, and D. M. Barbano. 1993. Feed and animal factors influencing milk fat composition. J. Dairy Sci. 76:1753-1771.

Sidhu, G. S., M. A. Brown, and A. R. Johnson. 1975. Autoxidation in milk rich in linoleic acid. 1. An objective method for measuring autoxidation and evaluating antioxidants. J. Dairy Res. $42: 185-195$
Singsaas, K., and G. Hadland. 1972. Bestemmelse af fedets syregrad I mælk ved B.D.I.-metoden. Mejeriposten 153:1-9.

Stapelfeldt, H., B. R. Nielsen, and L. H. Skibsted. 1997. Effect of heat treatment, water activity and storage temperature on the oxidative stability of whole milk powder. Int. Dairy J. 7:331-339.

Wiking, L., L. Björck, and J. H. Nielsen. 2003. Influence of feed composition on stability of fat globules during pumping of raw milk. Int. Dairy J. 13:797-803.

Wiking, L., M. B. Frøst, L. B. Larsen, and J. H. Nielsen. 2002. Effects of storage conditions on lipolysis, proteolysis and sensory attributes in high quality raw milk. Milchwissenscaft 57:190-194. 